\title{
Erratum to: Impacts of human activities on the evolution of estuarine wetland in the Yangtze Delta from 2000 to 2010
}

\author{
Lei Zhang • Bingfang Wu $\cdot$ Kai Yin •
}

Xiaosong Li $\cdot$ Kun Jia $\cdot$ Liang Zhu

Published online: 28 February 2015

(c) Springer-Verlag Berlin Heidelberg 2015

\section{Erratum to: Environ Earth Sci (2015) 73:435-447 \\ DOI 10.1007/s12665-014-3565-2}

The authors would like to correct the errors in the original publication as below.

The fifth author's name was incorrectly typed as "Kun Kia" instead of "Kun Jia". The fifth author's name should read as "Kun Jia".

The correct version of the authors' affiliations is given below:

Lei Zhang ${ }^{1}$. Bingfang $\mathrm{Wu}^{1} \cdot$ Kai $\mathrm{Yin}^{1} *$. Xiaosong $\mathrm{Li}^{1}$. $\mathrm{Kun} \mathrm{Jia}^{2} \cdot$ Liang $\mathrm{Zhu}^{1}$

1. Key Laboratory of Digital Earth Science, Institute of Remote Sensing and Digital Earth, Chinese Academy of Sciences, P. O. Box 9718, Beijing 100101, China. *Corresponding author: Tel.: +86 10 64842376, E-mail: yinkai@ radi.ac.cn

2. College of Global Change and Earth System Science, Beijing Normal University, Beijing 100875, China

The online version of the original article can be found under doi:10.1007/s12665-014-3565-2.

L. Zhang $\cdot$ B. Wu $\cdot$ K. Yin $(\bowtie) \cdot$ X. Li $\cdot$ L. Zhu

Key Laboratory of Digital Earth Science, Institute of Remote

Sensing and Digital Earth, Chinese Academy of Sciences,

P. O. Box 9718, Beijing 100101, China

e-mail: yinkai@radi.ac.cn

K. Jia

College of Global Change and Earth System Science, Beijing

Normal University, Beijing 100875, China 